\title{
KELAS IBU HAMIL TERHADAP PENGETAHUAN dan SIKAP IBU TENTANG PERAWATAN SELAMA KEHAMILAN, PERSALINAN dan NIFAS
}

\author{
Meidiawaty Siregar ${ }^{1}$, Masdewi Nasution $^{2}$ \\ Politeknik Kesehatan Kemenkes Medan ${ }^{12}$ \\ e-mail: ${ }^{1}$ meidiawaty77@gmail.com, ${ }^{2}$ masdewi@gmail.com
}

\begin{abstract}
Class pregnant women is study group mothers pregnant to the number of participants maximum of 10 people.The goal of research to know the influence of class pregnant women to knowledge and attitude pregnant women about care during pregnancy, childbirth and postpartum.

Research using quantitative methods with quasi experimental design using design of pre and post test. Population i.e. 133 pregnant women at work-area Community Health Centre, district of Pargarutan, South Tapanuli, divided into 2 groups of controls (which is not given a class of pregnant women) and treatment (given the intervention class of pregnant women).). Data analysis using the wilcoxon test on the level of significance of $\alpha=0.05$ to measure an increase in knowledge and attitudes about the care of pregnancy, labor and childbirth. Then use the chi-square test to see the differences of knowledge and attitudes about treatment during pregnancy, labor and childbirth in the treatment group and the control group.

Keywords :class pregnant women; knowledge; attitude; care during pregnancy; childbirth and parturition
\end{abstract}

\begin{abstract}
ABSTRAK
Kelas Ibu hamil adalah kelompok belajar ibu-ibu hamil dengan jumlah peserta maksimal 10 orang. Tujuan penelitian untuk mengetahui pengaruh kelas ibu hami lterhadap pengetahuan dan sikap ibu hamil tentang perawatan selama kehamilan, persalinan dan nifas.

Penelitian menggunakan metode kuantitatif dengan desain kuasi eksperime nmenggunakan rancangan pre dan post-test.Populasi yaitu 133 ibu hamil di wilayah kerja Puskesmas Pargarutan, Kabupaten Tapanuli Selatan, dibagi menjadi 2 kelompok kontrol (yang tidak diberikan kelas ibu hamil) dan perlakuan (diberikan intervensi kelas ibu hamil). Analisis data menggunakan uji Wilcoxon dengan $\alpha=0,05$ untuk mengukur peningkatan pengetahuan dan sikap tentang perawatan kehamilan, persalinan dan nifas.Kemudian menggunakan uji chisquare untuk melihat perbedaan pengetahuan dan sikap tentang perawatan selama kehamilan persalinan dan nifas pad akelompok perlakuan dan kelompok kontrol.
\end{abstract}

Kata Kunci : kelas ibu hamil; pengetahuan; sikap; perawatan selama kehamilan; persalinan dan nifas

\section{PENDAHULUAN \\ 1.1 Latar Belakang}

Tingginya angka kematian ibu dan angka kematian bayi juga disebabkan ketidakberdayaan seorang ibu dalam memutuskan untuk mendapatkan pertolongan medis apabila terjadi permasalahan pada kehamilan dan bayinya. Hal ini antara lain disebabkan oleh rendahnya pengetahuan ibu dalam perawatan kesehatan ibu serta pengenalan tanda-tanda bahaya obstetri dan neonatal, sehingga akan menghambat suatu keputusan yang harus diambil oleh ibu sehingga dapat membahayakan ibu dan bayinya. Dalam upaya menurunkan angka kematian pada ibu dan bayi pemerintah meluncurkan sebuah program yaitu kelas ibu hamil. Indonesia sudah mulai menerapkan metode pembelajaran kelas ibu hamil di berbagi wilayah mulai tahun 2009.
Menurut Kemkes RI (2012), kelas ibu hamil adalah kelompok belajar ibu-ibu hamil dengan jumlah peserta maksimal 10 orang. Di kelas ini ibu-ibu hamil akan belajar bersama, diskusi dan tukar pengalaman tentang KIA secara menyeluruh dan sistematis serta dapat dilaksanakan secara terjadwal dan berkesinambungan. Kelas ibu hamil difasilitasi oleh bidan/tenaga kesehatan dengan menggunakan paket kelas ibu hamil yaitu buku KIA, flipchart (lembar balik), pedoman pelaksanaan kelas ibu hamil, dan pegangan fasilitator kelas ibu hamil. Menurut Kemkes RI (2012), tujuan umum kelas ibu hamil adalah meningkatkan pengetahuan, merubah sikap dan perilaku ibu agar memahami tentang pemeriksaan dan perawatan kehamilan agar ibu dan janin sehat, persalinan aman, nifas nyaman ibu selamat, bayi sehat, pencegahan penyakit fisik dan jiwa, gangguan gizi dan komplikasi kehamilan, persalinan, dan nifas agar ibu dan bayi sehat, perawatan bayi baru lahir 
agar tumbuh kembang optimal, serta aktivitas fisik ibu hamil.

Kelas Ibu Hamil melalui programprogramnya dapat membantu ibu hamil untuk meningkatkan pengetahuannya mengenai seputar kehamilan, melahirkan dan masa nifas. Pengetahuan adalah hasil "tahu" dan ini terjadi setelah orang melakukan pengindraan terhadap suatu objek tertentu. Sebagian besar pengetahuan manusia diperoleh melalui mata dan telinga (Maulana, 2007). Hasil penelitian yang dilakukan oleh Hastuti, dkk (2011) dan Harahap (2016) juga menyatakan bahwa terdapat pengaruh kelas ibu hamil terhadap pengetahuan ibu hamil.

Sikap ibu hamil terhadap kehamilan, fase melahirkan, dan masa nifas juga sangat perlu ditingkatkan dalam upaya menekan angka kematian ibu dan bayi. Sikap ibu dapat dibentuk melalui kelas ibu hamil. Sikap merupakan kesiapan atau kesediaan untuk bertindak dan bukan merupakan pelaksanaan motif tertentu (Notoatmodjo, 2007). Hasil penelitian yang dilakukan oleh Hastuti, dkk (2011) dan Harahap (2016) juga menyatakan bahwa terdapat pengaruh kelas ibu hamil terhadap sikap ibu hamil.

Indikator cakupan K4 memperlihatkan akses ibu hamil terhadap pelayanan kesehatan dan tingkat kepatuhan ibu hamil dalam memeriksakan kehamilannya ke tenaga kesehatan. Secara nasional, indikator cakupan pelayanan kesehatan ibu hamil K4 pada tahun 2013 yaitu sebesar 86,85 \% belum mencapai target Rencana Strategis (Renstra) Kementerian Kesehatan (Kemkes) tahun yang sama yakni sebesar 93 \% (Kemkes RI, 2014). Cakupan K4 di Provinsi Sumatera Utara pada tahun 2013 hanya $88,7 \%$ juga belum mencapai target Renstra Kemkes di tahun yang sama (Dinkes Provinsi Sumatera Utara, 2014).

Pada tahun 2016 menunjukkan cakupan K4 di wilayah kerja Puskesmas Pargarutan menjadi sebesar 57,3 \%. Namun kunjungan K4 tersebut lebih rendah dari cakupan K4 Kabupaten Tapanuli Selatan sebesar 68,77\%. Selain itu, masih terdapat kematian ibu di wilayah kerja Puskesmas Pargarutan sebanyak dua dari dua puluh kematian ibu di Kabupaten Tapanuli Selatan Tahun 2015.

Secara nasional cakupan pertolongan persalinan oleh tenaga kesehatan mengalami kenaikan di tahun 2013 menjadi sebesar 90,88\%, dimana persentasenya bahkan melebihi cakupan K4 (Kemkes RI, 2014). Di wilayah kerja Puskesmas Pargarutan juga menunjukkan cakupan pertolongan persalinan oleh tenaga kesehatan yang lebih tinggi dari cakupan K4 yaitu sebesar 58,5\% (Dinkes Kabupaten Tapanuli Selatan, 2015). Hal ini menunjukkan bahwa masih banyak ibu hamil yang datang ke tenaga kesehatan hanya untuk bersalin tanpa pernah melakukan pemeriksaan kehamilan. Padahal jika seorang ibu datang langsung untuk bersalin di tenaga kesehatan tanpa adanya riwayat pelayanan antenatal sebelumnya, maka faktor resiko dan kemungkinan komplikasi saat persalinan akan lebih sulit diantisipasi. Implementasi kelas ibu hamil ini diharapkan mampu merubah perilaku ibu hamil dalam pemanfaatan pelayanan kesehatan.

Pada survei awal yang dilakukan pada $11 \mathrm{ibu}$ hamil yang berkunjung ke Posyandu Desa Sijungkang (salah satu wilayah kerja Puskesmas Pargarutan bulan Februari 2019 dengan latar belakang pendidikan 9 orang sekolah menengah umum (SMU) dan 3 orang sekolah menengah pertama (SMP), didapatkan hasil hanya 3 orang $(20 \%)$ ibu hamil dengan pendidikan SMU yang mampu menjawab pertanyaan meliputi berapa kali idealnya seorang ibu hamil memeriksakan kehamilannya selama hamil minimal 4 kali, persiapan persalinan harus terprogram melalui persiapan persalinan dan pencegahan komplikasi (P4K) serta persiapan fisik dan psikologis, perawatan post partum dimulai sejak 1 jam setelah lahirnya plasenta dampai dengan 6 minggu (42 hari) setelah itu, sedangkan 8 orang ibu hamil tidak mampu menjawab pertanyaan dengan benar.

Dari sikap 11 ibu hamil yang diwawancara diperoleh hasil 8 orang $(70 \%)$ menunjukkan sikap tidak penting memeriksakan kehamilan ke bidan atau tenaga kesehatan walaupun penting bersalin di tenaga kesehatan dan 3 orang (30\%) menunjukkan respon baik bahwa memeriksakan kehamilan harus sejak awal ke tenaga kesehatan.

Pada tahun 2016 kematian ibu diwilayah kerja Puskesmas Pargarutan sebanyak 1 orang dari 12 orang kematian ibu di Kabupaten Tapanuli Selatan. Sedangkan pada tahun 2015 terjadi peningkatan jumlah kematian ibu di Kabupaten Tapanuli Selatan dai 12 menjadi 20 orang ibu. Upaya yang dapat dilakukan ialah dengan melakukan kelas ibu hamil di Puskesmas Pargarutan.Kelas ibu hamil adalah program seperti memberi materi tentang perawatan kehamilan, persalinan, dan nifas sehingga dapat diketahui bagaimana pengaruh kelas ibu terhadap pengetahuan dan sikap ibu tentang pemeriksaan dan perawatan kehamilan, persalinan dan nifas di wilayah kerja Puskesmas Pargarutan Kabupaten Tapanuli Selatan tahun 2018.

Penerapan kelas ibu hamil diharapkan dapat meningkatkan aksesibitas ibu hamil terhadap pelayanan kesehatan ibu dan anak yang berkualitas sehingga dapat menjadi salah satu upaya dalam penurunan AKI dan AKB. Pengaruh yang terjadi dari pemberian materi kelas ibu hamil yang disampaikan secara komprehensif dan berkesinambungan diharapkan terjadi peningkatan pengetahuan, 
perubahan sikap dan perilaku ibu hamil dalam perawatan kehamilan, persalinan, dan nifas.

Berdasarkan Permasalahan diatas, maka penulis tertarik untuk meneliti tentang "Pengaruh Kelas Ibu Hamil terhadapPengetahuan dan Sikap Ibu tentang Perawatan selama Kehamilan, Persalinandan Nifas di wilayah kerja Puskesmas Pargarutan Kabupaten Tapanuli Selatan”.

\subsection{Rumusan Masalah}

Dari latar belakang yang telah diuraikan di atas, maka penulis merumuskan masalah penelitian yaitu "Apakah pengaruh kelas ibu hamil terhadap pengetahuan dan sikap ibu tentang perawatan selama kehamilan, Persalinan dan Nifas di wilayah kerja Puskesmas Pargarutan Kabupaten Tapanuli Selatan Tahun 2019 “.

\subsection{Tujuan Penelitian.}

"Untuk mengetahui pengaruh kelas ibu hamil terhadap pengetahuan dan sikap ibu tentang perawatan selama kehamilan, Persalinan dan Nifas di wilayah kerja Puskesmas Pargarutan Kabupaten Tapanuli Selatan Tahun 2019 “.

\subsection{Manfaat Penelitian}

1. Bagi Intitusi Pendidikan

Dapat menjadi masukan dalam pengembangan ilmu kebidanan serta dapat menambah referensi perpustakaan yang telah ada

2. Bagi Petugas Kesehatan atau Bidan

Dapat dijadikan sebagai pedoman bagi petugas kesehatan atau bidan di daerah Kota Padangsidimpuan dalam meningkatkan kesiapan ibu terutama dalam menghadapi persalinan.

\section{Bagi Ibu Hamil}

Dapat menambah pengetahuan dan wawasan ibu hamil mengenai pentingnya mempersiapkan segala sesuatu yang ibu dan keluarga persiapkan sebelum persalinan berlangsung.

\section{TINJAUAN PUSTAKA}

\subsection{Kelas Ibu Hamil}

\subsubsection{Pengertian Kelas Ibu Hamil}

Menurut Kemkes RI (2012), kelas ibu hamil adalah kelompok belajar ibu-ibu hamil dengan jumlah peserta maksimal 10 orang. Di kelas ini ibu-ibu hamil akan belajar bersama, diskusi dan tukar pengalaman tentang KIA secara menyeluruh dan sistematis serta dapat dilaksanakan secara terjadwal dan berkesinambungan. Kelas ibu hamil difasilitasi oleh bidan/tenaga kesehatan dengan menggunakan paket kelas ibu hamil yaitu buku KIA, flipchart (lembar balik), pedoman pelaksanaan kelas ibu hamil, dan pegangan fasilitator kelas ibu hamil. Beberapa keuntungan kelas ibu hamil adalah :

1. Materi diberikan secara menyeluruh dan terencana sesuai dengan pedoman kelas ibu hamil.

2. Materi lebih komprehensif sehingga memudahkan petugas kesehatan dalam persiapan pelaksanaan kelas ibu hamil sebelum penyajian materi.

3. Dapat mendatangkan tenaga ahli untuk memberikan penjelasan mengenai topik tertentu.

4. Ada interaksi antara petugas kesehatan dengan ibu hamil pada saat pembahasan materi dilaksanakan.

5. Dilaksanakan secara berkala dan berkesinambungan.

6. Dilakukan evaluasi terhadap petugas kesehatan dan ibu hamil dalam memberikan penyajian sehingga dapat meningkatkan kualitas sistem pembelajaran.

\section{TINJAUAN PUSTAKA \\ 2.1 Pengetahuan \\ 2.1.1 Definisi Pengetahuan}

Pengetahuan adalah hasil "tahu" dan ini terjadi setelah orang melakukan pengindraan terhadap suatu objek tertentu. Pengindraan terjadi melalui pancaindra manusia, yakni indera penglihatan, pendengaran, penciuman, rasa dan raba. Sebagian basar pengetahuan manusia diperoleh melalui mata dan telinga (Maulana, 2007).

\subsection{Sikap \\ 2.2.1 Pengertian Sikap}

Sikap merupakan reaksi atau respon yang masih tertutup dari seseorang terhadap stimulus atau objek. Newcomb salah seorang ahli psikologi sosial, menyatakan bahwa sikap itu merupakan kesiapan atau kesediaan untuk bertindak dan bukan merupakan pelaksanaan motif tertentu (Notoatmodjo, 2007).

\subsection{Landasan Teori}

Perilaku adalah apa yang dikerjakan oleh mahluk hidup, baik yang diamati secara langsung atau tidak langsung, perilaku manusia dapat dilihat dari 3 aspek yaitu: aspek fisik, psikis dan sosial yang secara terinci merupakan refleksi dari berbagai gejolak kejiwaan seperti pengetahuan, motivasi, persepsi, sikap dan sebagainya, yang ditentukan dan dipengaruhi oleh faktor pengalaman, keyakinan, sarana fisik dan sosial budaya masyarakat. Bahkan kegiatan internal seperti berpikir, berpersepsi dan emosi juga merupakan perilaku manusia.

Notoatmodjo (2010) mengutip Skinner (1938), berpendapat perilaku merupakan respons atau reaksi seseorang terhadap stimulus (rangsangan dariluar). 
Dengan demikian perilaku manusia terjadi melalui proses :

Stimulus $->$ Organisme $\rightarrow$ Respons, sehingga teori Skinner ini disebut teori "S-O-R" (stimulusorganisme-respons).

Berdasarkan teori "S-O-R" tersebut, maka perilaku manusia dapatdikelompokkan menjadi perilaku tertutup (covert behavior) dan perilaku terbuka (overt behavior). Perilaku tertutup terjadi bila respons terhadap stimulus tersebut masih belum dapat diamati orang lain (dari luar) secara jelas. Respons seseorang masih terbatas dalam bentuk perhatian, perasaan, persepsi, pengetahuan dan sikap terhadap stimulus yang bersangkutan.Bentuk perilaku tertutup yang dapat diukur adalah pengetahuan dan sikap.

Contohnya ibu hamil mengetahui pentingnya pemeriksaan kehamilan untuk kesehatan bayi dan dirinya sendiri adalah merupakan pengetahuan (knowledge).Kemudian ibu tersebut bertanya kepada tetangganya dimana tempat periksa kehamilan yang dekat.Ibu bertanya tentang tempat dimana pemeriksaan kehamilan itu dilakukan adalah sebuah kecenderungan untuk melakukan pemeriksaan kehamilan, yang selanjutnya disebut sikap (attitude).Teori S-O-R dapat dilihat pada Gambar 2.1.

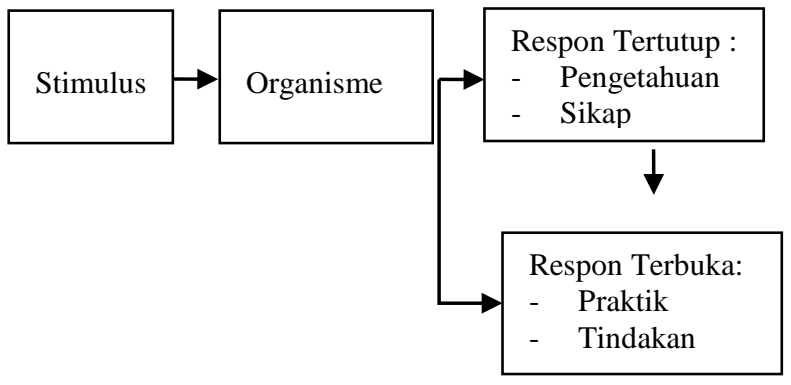

Gambar 2.3Teori stimulusorganismerespons(S-O-R)

\subsection{Kerangka Konsep}

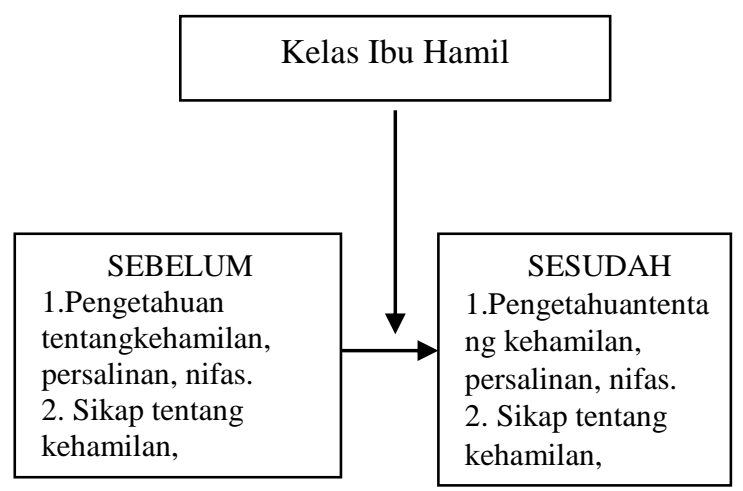

Dalamkerangkakonsepyang ingindiketahuiadalahbagaimanatingkatpengetahuan dan sikap tentang perawatan kehamilan, persalinan, dan nifas sebelumdan sesudah mengikuti kelas ibu hamil.

\section{METODE PENELITIAN \\ 3.1 Desain Penelitian}

Jenis penelitian ini adalah penelitian kuantitatif dengan desain penelitian kuasi eksperimental yang menggunakan rancangan pre and post- test, sesudah dilakukan observasi pertama (pre-test) kemudian peneliti dapat menguji perubahan-perubahan yang terjadi setelah adanya perlakuan (post-test).Penelitian ini menggunakan dua kelompok, yaitu kelompok yang diberi perlakuan dengan metode ceramah dan kelompok tanpa perlakuan (kelompok kontrol). Rancangan penelitian ini dapat digambarkan sebagai berikut :

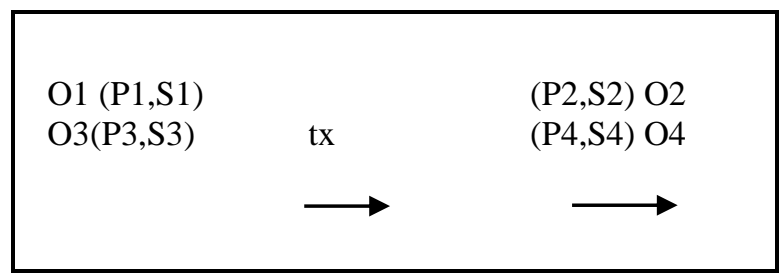

Gambar 3.1 Desain penelitian

Keterangan:

$\mathrm{O} 1(\mathrm{P} 1, \mathrm{~S} 1)=$ Pre-test, yaitu pengukuran pengetahuan dan sikap ibu tentang perawatan kehamilan, persalinan, dan nifas tanpa pemberian perlakuan/intervensi pada kelompok kontrol.

$\mathrm{O} 2(\mathrm{P} 2, \mathrm{~S} 2)=$ Post-test, yaitu pengukuran pengetahuan dan sikap ibu tentang perawatan kehamilan, persalinan, dan nifas tanpa pemberian perlakuan/intervensi pada kelompok kontrol.

$\mathrm{O} 3(\mathrm{P} 3, \mathrm{~S} 3)=$ Pengukuran pengetahuan dan sikap ibu tentang perawatan kehamilan,persalinan, dan nifas sebelum pemberian perlakuan/intervensi.

$\mathrm{O} 4(\mathrm{P} 3, \mathrm{~S} 3)=$ Pengukuran pengetahuan dan sikap ibu tentang perawatan kehamilan,persalinan, dan nifas setelah pemberian perlakuan/intervensi.

$\mathrm{tx}=$ Intervensi yang dilakukan yaitu kelas ibu hamil

\subsection{Lokasi dan Waktu Penelitian 3.2.1 Lokasi Penelitian}

Penelitian dilaksanakan di wilayah kerja Puskesmas Pargarutan KabupatenTapanuli Selatan yaitu sebanyak 8 desa dan 2 Kelurahan.

\subsubsection{Waktu Penelitian}

Waktu penelitian dilaksanakanpada bulan Januari sampai dengan Agustus2019 


\subsection{Populasi dan Sampel 3.3.1 Populasi}

Populasi dalam penelitian ini adalah seluruh ibu hamil diatas trimester II di wilayah kerja Puskesmas Pargarutan Kabupaten Tapanuli Selatan tahun 2019 yang berjumlah 68 orang.

\subsubsection{Sampel}

Pada penelitian ini pengambilan sampel sebanyak 68 orang ditentukan dengan total sampling yaitu teknik penentuan sampel bila semua anggota populasi digunakan sebagai sampel. Oleh karena itu, sampel yang digunakan dalam penelitian ini yaitu seluruh ibu hamil trimester II di wilayah kerja Puskesmas Pargarutan di tahun 2019. Kemudian dari jumlah seluruh ibu hamil yang ada akan dibagi menjadi 2 kelompok yaitu kelompok perlakuan berjumlah 34 orang dan kelompok kontrol berjumlah 34 orang. Pada kelompok perlakuan akan dibagi menjadi 4 kelompok yaitu menjadi 8 atau 9 orang setiap kelompok karena pada satu kelas ibu hamil maksimal berjumlah 10 orang.

\subsection{Metode Pengumpulan Data 3.4.1 Alat Penumpul Data}

Alat pengumpul data dalam penelitian ini adalah kuesioner yang berisi sejumlah pertanyaan. Kuesioner yang akan dipakai untuk ibu hamil diadopsi dari kuesioner evaluasi kelas ibu hamil pada pedoman pelaksanaan kelas ibu hamil Kemenkes RI kemudian dimodifikasi sesuai kebutuhan, terdiri dari pertanyaanterstruktur yang mengkaji pengetahuan dan sikap ibu tentang perawatan selama kehamilan, persalinan dan nifas.

Dari hasil uji validitas dan reliabilitas diketahui bahwa dari seluruh pertanyaan pengetahuanmempunyai nilai corrected item total correlation lebih besar dari nilai tabel $(\mathrm{r}$ tabel $=0,361)$ dengan nilai cronbach alpha lebih besar dari 0,60 yang berarti bawah seluruh pertanyaan adalah valid dan reliabel.

Pernyataa sikap mempunyai nilai corrected item total correlation lebih besar dari nilai table ( $\mathrm{r}$ tabel $=0,361$ ) dengan nilai cronbach alpha lebih besar dari 0,60 yang berarti bawah seluruh pertanyaan adalah valid dan reliabel.

\subsection{Metode Analisis Data}

Data yang telah dikumpulkan akan dilakukan analisis statistik dengan menggunakan tahapan analisis univariat, bivariat dan evaluasi kelas Ibu hamil.

\begin{tabular}{|c|c|c|c|c|c|}
\hline \multirow{2}{*}{ No } & \multirow{2}{*}{$\begin{array}{c}\text { Pengetahuan Kelompok } \\
\text { Kontrol }\end{array}$} & \multicolumn{2}{|c|}{ Pre Test } & \multicolumn{2}{c|}{ Post Test } \\
\cline { 3 - 6 } & Baik & - & - & - & - \\
\hline 1 & Cukup & 2 & 5,9 & 3 & 8,8 \\
\hline 2 & Kurang & 32 & 94,1 & 31 & 91,2 \\
\hline 3 & Total & $\mathbf{3 4}$ & $\mathbf{1 0 0}$ & $\mathbf{3 4}$ & $\mathbf{1 0 0}$ \\
\hline \multicolumn{2}{r|r}{} \\
\hline
\end{tabular}

IV. HASIL PENELITIAN DAN PEMBAHASAN

4.1 Analisis Univariat

4.1.1 Distribusi Kategori Pengetahuan dan Sikap

Kelompok Kontrol tentang Perawatan Kehamilan, Persalinan dan Nifas di Wilayah Kerja Puskesmas Pargarutan Kabupaten Tapanuli Selatan Tahun 2016

Tabel 4.1 Kategori pengetahuan kelompok kontrol pretest dan posttest tentang perawatan kehamilan, persalinan, dan nifas di wilayah kerja

Berdasarkan tabel diatas dapat dilihat bahwa pada pengetahuan kelompok kontrol pretest sebanyak 2 orang responden $(5,9 \%)$ memiliki pengetahuan yang cukup tentang perawatan kehamilan, persalinan dan nifas di wilayah kerja Puskesmas Pargarutan Kabupaten TapanuliSelatan dan sebanyak 32 orang responden $(94,1 \%)$ memiliki pengetahuan yang kurang tentang perawatan kehamilan, persalinan dan nifas di wilayah kerja Puskesmas Pargarutan Kabupaten Tapanuli Selatan. Sedangkan pengetahuan kelompok kontrol (post test) sebanyak 3 orang

\begin{tabular}{|c|c|c|c|c|c|}
\hline \multirow{2}{*}{ No } & Sikap Kelompok & \multicolumn{2}{|c|}{ Pre Test } & \multicolumn{2}{|c|}{ Post Test } \\
\cline { 3 - 6 } & Kontrol & $\mathrm{n}$ & $\%$ & $\mathrm{n}$ & $\%$ \\
\hline 1 & Baik & 6 & 17,6 & 5 & 14,7 \\
\hline 2 & Kurang & 28 & 82,4 & 29 & 85,3 \\
\hline & Total & $\mathbf{3 4}$ & $\mathbf{1 0 0}$ & $\mathbf{3 4}$ & $\mathbf{1 0 0}$ \\
\hline
\end{tabular}

responden $(8,8 \%)$ memiliki pengetahuan yang cukup tentang perawatan kehamilan, persalinan dan nifas, dan 31 orang responden $(91,2 \%)$ memiliki pengetahuan yang kurang tentang perawatan kehamilan, persalinan dan nifas di wilayah kerja Puskesmas Pargarutan Kabupaten TapanuliSelatan.

Tabel 4.2 Kategori sikap kelompok kontrol pretest dan posttest tentang perawatan kehamilan, persalinan dan nifas di wilayah kerja puskesmas pargarutan kabupaten tapanuli selatan

Berdasarkan tabel diatas dapat dilihat bahwa pada sikap kelompok kontrol pretest sebanyak 6 orang responden $(17,6 \%)$ memiliki sikap baik tentang perawatan kehamilan, persalinan dan nifas di wilayah kerja puskesmas Puskesmas Pargarutan Kabupaten TapanuliSelatandan sebanyak 28 orang responden $(82,4 \%)$ memiliki sikap yang kurang tentang perawatan kehamilan, persalinan dan nifas di wilayah 
kerja Puskesmas Pargarutan Kabupaten TapanuliSelatan. Sedangkan sikap kelompok kontrol (posttest) bahwa sebanyak 5 orang responden $(14,7 \%)$ memiliki sikap baik tentang perawatan kehamilan, persalinan dan nifas, dan 29 orang responden (85,3 $\%)$ memiliki sikap yang kurang tentang perawatan kehamilan, persalinan dan nifas di wilayah kerja Puskesmas Pargarutan Kabupaten Tapanuli Selatan.

4.1.2 Distribusi kategori pengetahuan dan sikap kelompok perlakuan tentang perawatan

\begin{tabular}{|c|c|c|c|c|c|}
\hline \multirow{2}{*}{ No } & \multirow{2}{*}{$\begin{array}{c}\text { Pengetahuan } \\
\text { Kelompok } \\
\text { Perlakuan }\end{array}$} & \multicolumn{2}{|c|}{ Pre Test } & \multicolumn{2}{c|}{ Post Test } \\
\cline { 3 - 6 } & $\mathrm{n}$ & $\%$ & $\mathrm{n}$ & $\%$ \\
\hline 1 & Baik & - & - & - & - \\
\hline 2 & Cukup & 5 & 14,7 & 26 & 76,5 \\
\hline 3 & Kurang & 29 & 85,3 & 8 & 23,5 \\
\hline \multicolumn{2}{r|}{ Total } & $\mathbf{3 4}$ & $\mathbf{1 0 0}$ & $\mathbf{3 4}$ & $\mathbf{1 0 0}$ \\
\hline
\end{tabular}

kehamilan, persalinan dan nifas di wilayah kerja puskesmas pargarutan kabupaten tapanuli selatan tahun 2016

Hasil pengukuran pengetahuan dan sikap kelompok perlakuan tentang perawatan kehamilan, persalinan, dan nifas kemudian dikategorikan pada tabel dibawah ini:

Tabel 4.3 Kategori pengetahuan kelompok perlakuan pretest dan posttest tentang perawatan kehamilan, persalinan, dan nifas di wilayah kerja puskesmas pargarutan kabupaten tapanuli selatan

Berdasarkan tabel 4.3 dapat dilihat bahwa pada pengetahuan kelompok perlakuan pretest sebanyak 5 orang responden $(14,7 \%)$ memiliki pengetahuan yang cukup tentang perawatan kehamilan, persalinan dan nifas di wilayah kerja Puskesmas Pargarutan Kabupaten Tapanuli Selatan dan sebanyak 29 orang responden $(85,3 \%)$ memiliki pengetahuan yang kurang tentang perawatan kehamilan, persalinan dan

\begin{tabular}{|c|c|c|c|c|c|}
\hline \multirow{2}{*}{ No } & \multirow{2}{*}{ Sikap Kelompok Perlakuan } & \multicolumn{2}{|c|}{ Pre Test } & \multicolumn{2}{|c|}{ Post Test } \\
\hline & & $\mathrm{n}$ & $\%$ & $\mathrm{n}$ & $\%$ \\
\hline 1 & Baik & 12 & 35,3 & 29 & 85,3 \\
\hline 2 & Kurang & 22 & 64,7 & 5 & 14,7 \\
\hline & Total & 34 & 100 & 34 & 100 \\
\hline
\end{tabular}

nifas di wilayah kerja Puskesmas Pargarutan Kabupaten Tapanuli Selatan. Sedangkan sikap kelompok kontrol (posttest) bahwa sebanyak 26 orang responden $(76,5 \%)$ memiliki pengetahuan yang cukup tentang perawatan kehamilan, persalinan dan nifas, dan 8 orang responden $(23,5 \%)$ memiliki sikap yang kurang tentang perawatan kehamilan, persalinan dan nifas di wilayah kerja Puskesmas Pargarutan Kabupaten Tapanuli Selatan.

Tabel 4.4 Kategori sikap kelompok perlakuan pretest dan posttest tentang perawatan kehamilan, persalinan dan nifas di wilayah kerja puskesmas pargarutan kabupaten tapanuli selatan

Berdasarkan tabel 4.4 diatas dapat dilihat bahwa pada sikap kelompok kontrol pretest sebanyak 12 orang responden $(35,3 \%)$ memiliki sikap baik tentang perawatan kehamilan, persalinan dan nifas di wilayah kerja Puskesmas Pargarutan Kabupaten Tapanuli Selatan dan sebanyak 22 orang responden $(64,7 \%)$ memiliki sikap yang kurang tentang perawatan kehamilan, persalinan dan nifas di wilayah kerja Puskesmas Pargarutan Kabupaten Tapanuli Selatan. Sedangkan sikap kelompok kontrol (posttest) bahwa sebanyak 29 orang responden (85,3 \%) memiliki sikap baik tentang perawatan kehamilan, persalinan dan nifas, dan 5 orang responden $(14,7 \%)$ memiliki sikap yang kurang tentang perawatan kehamilan, persalinan dan nifas di wilayah kerja Puskesmas Pargarutan Kabupaten Tapanuli Selatan.

\subsection{Analisis Bivariat}

4.2.1 Pengetahuan dan Sikap Responden tentang Perawatan Kehamilan,Persalinan dan Nifas pada Kelompok Kontrol dan Kelompok Perlakuan Sebelum Kelas ibu hamil

Untuk melihat perbedaan pengetahuan dan sikap responden pada kelompok perlakuan dan kontrol sebelum kelas ibu hamil dilakukan dengan menggunakan uji chi-square. Hasil analisis uji dapat dilihat pada tabel dibawah ini:

Tabel 4.5 Tabulasi silang pengetahuan tentang perawatan kehamilan, persalinan, dan nifas pada kelompok perlakuan dan kelompok kontrol sebelum kelas ibu hamil

\begin{tabular}{|c|c|c|c|c|c|c|c|}
\hline \multirow{3}{*}{ Pengetahuan } & \multicolumn{4}{|c|}{ Kelompok } & \multirow{2}{*}{ Jumlah } & \multirow{2}{*}{\begin{tabular}{c} 
Nilai \\
\cline { 2 - 7 }
\end{tabular}} & \multicolumn{2}{|c|}{ Kontrol } & \multicolumn{2}{|c|}{ Perlakuan } & \multicolumn{1}{|c|}{ P } \\
\cline { 2 - 7 } & $\mathrm{n}$ & $\mathbf{\%}$ & $\mathrm{n}$ & $\mathbf{\%}$ & $\mathrm{n}$ & $\mathbf{\%}$ & \\
\hline kurang & 32 & 52,4 & 29 & 47,6 & 61 & 100 & \multirow{2}{*}{0.276} \\
\hline cukup & 2 & 28,6 & 5 & 71,4 & 7 & 100 & \\
\hline
\end{tabular}

Berdasarkan tabel 4.5 di atas diperoleh sebagian besar pengetahuan dalam kategori kurang yaitu 61 responden dimana pada kelompok kontrol sebanyak 32 responden $(52,4 \%)$ dan kelompok perlakuan sebanyak 29 responden $(47,6 \%)$. Hasil uji chi-square diperoleh nilai $p=0,276>\alpha(0,05)$, sehingga dapat disimpulkan bahwa tidak terdapat 
perbedaan pengetahuan antara kelompok perlakuan dan kontrol sebelum kelas ibu hamil.

Tabel 4.6 Tabulasi silang sikap tentang perawatan kehamilan, persalinan, dan nifas pada kelompok perlakuan dan kelompok kontrol sebelum kelas ibu hamil

\begin{tabular}{|c|c|c|c|c|c|c|c|}
\hline \multirow{3}{*}{ Sikap } & \multicolumn{4}{|c|}{ Kelompok } & \multirow{2}{*}{\multicolumn{2}{|c|}{ Jumlah }} & \multirow{3}{*}{$\begin{array}{l}\text { Nilai } \\
\text { P }\end{array}$} \\
\hline & \multicolumn{2}{|c|}{ Kontrol } & \multicolumn{2}{|c|}{ Perlakuan } & & & \\
\hline & $\mathrm{n}$ & $\%$ & $\mathrm{n}$ & $\%$ & $\mathrm{n}$ & $\%$ & \\
\hline baik & 6 & 33,3 & 12 & 66,7 & 18 & 100 & \\
\hline kurang & 28 & 56 & 22 & 44 & 50 & 100 & 0,14 \\
\hline
\end{tabular}

Berdasarkan tabel di atas diperoleh sebagian besar sikap dalam kategori kurang yaitu 50 orang responden dimana pada kelompok kontrol sebanyak 28 responden $(56 \%)$ dan kelompok perlakuan sebanyak 22 responden (44\%). Hasil uji chi-square diperoleh nilai $p=0,140>\alpha(0,05)$, sehingga dapat disimpulkan bahwa tidak terdapat perbedaan pengetahuan antara kelompok perlakuan dan kontrol sebelum kelas ibu hamil.

\subsection{Perubahan Pengetahuan dan Sikap pada Kelompok Kontrol Sebelum dan Sesudah Test}

Untuk melihat perubahan pengetahuan dan sikap pada kelompok kontrol sebelum dan sesudah kelas ibu hamil dilakukan dengan menggunakan uji Wilcoxon. Hasil analisis dapat dilihat pada tabel dibawah ini

Tabel 4.7 Perubahan pengetahuan pada kelompok kontrol sebelum dan sesudah test

\begin{tabular}{|c|c|c|c|c|}
\hline \multirow{2}{*}{ Pengetahuan } & Sebelum & Sesudah & Perubahan & \multirow{2}{*}{$\begin{array}{c}\text { Nilai } \\
P\end{array}$} \\
\hline & $\mathrm{n}$ & $\mathrm{n}$ & Rangking & \\
\hline Cukup & 2 & 3 & $\begin{array}{c}\text { Rangking } \\
\text { Negatif = } \\
13\end{array}$ & \multirow{3}{*}{0,472} \\
\hline \multirow[t]{2}{*}{ Kurang } & 32 & 31 & $\begin{array}{c}\text { Rangking } \\
\text { Positif = } \\
10\end{array}$ & \\
\hline & & & Ties $=11$ & \\
\hline
\end{tabular}

Berdasarkan tabel di atas diperoleh keseluruhan pengetahuan sebelum kelas ibu hamil dalam kategori kurang yaitu 32 responden dan pengetahuan sesudah kelas ibu hamil semua responden dalam kategori kurang sebanyak 32 responden. Keterangan Uji Wilcoxon Perubahan pengetahuan :

1. Ranking negatif adalah perubahan pengetahuan sebelum dan sesudah dari kategori "cukup menjadi kurang", atau kategori "baik menjadi kurang”, atau kategori "baik menjadi cukup".
2. Ranking positif adalah perubahan pengetahuan

\begin{tabular}{|c|c|c|c|c|}
\hline \multirow{2}{*}{ Sikap } & Sebelum & Sesudah & Perubahan & \multirow{2}{*}{$\begin{array}{c}\text { Nilai } \\
\mathrm{P}\end{array}$} \\
\hline & $\mathrm{n}$ & $\mathrm{n}$ & Rangking & \\
\hline Baik & 6 & 5 & $\begin{array}{c}\text { Rangking Negatif } \\
=5\end{array}$ & \multirow{3}{*}{0,414} \\
\hline Kurang & 28 & 29 & $\begin{array}{c}\text { Rangking Positif } \\
=5\end{array}$ & \\
\hline & & & Ties $=24$ & \\
\hline
\end{tabular}

sebelum dan sesudah dari kategori "kurang menjadi cukup", atau kategori "kurang menjadi baik", atau kategori "cukup menjadi baik".

3. Ties artinya tidak terjadi perubahan sebelum dan sesudah kelas ibu hamil

Pada tabel diatas dilakukan uji wilcoxon untuk melihat perubahan tingkat pengetahuan, dari hasil analisis menunjukkan bahwa ada perubahan dari kategori tinggi ke kategori rendah sebanyak 13 orang responden, ada perubahan dari kategori rendah ketinggi sebanyak 10 orang responden, dan terjadi kategori yang tidak berubah sebanyak 11 orang responden, dengan kategori pengetahuan "cukup" sebelum dan sesudah yang dilakukan pada 34 orang responden. Hasil uji wilcoxon menunjukkan p $(0,475)$ $>\alpha(=0,05)$. Artinya tidak ada perubahan pengetahuan pada kelompok kontrol sebelum dan sesudah kelas ibu hamil.

Tabel 4.8 Perubahan sikap pada kelompok kontrol sebelum dan sesudahkelas ibu hamil

Berdasarkan tabel di atas diperoleh sikap sebelum kelas ibu hamil sebagian besar dalam kategori kurang yaitu 28 responden sebelum kelas ibu hamil dan menjadi 29 responden sesudah kelas ibu hamil, sementara 6 responden memiliki sikap baik sebelum kelas menjadi 5 responden sesudah kelas ibu hamil.

Keterangan Uji Wilcoxon

Perubahan sikap :

1. Ranking negatif adalah perubahan sikap sebelum dan sesudah dari kategori "baik menjadi kurang".

2. Ranking positif adalah perubahan sikap sebelum dan sesudah dari kategori "kurang menjadi baik".

3. Ties artinya tidak terjadi perubahan sebelum dan sesudah kelas ibu hamil

Pada tabel diatas dilakukan uji wilcoxon untuk melihat perubahan sikap, dari hasil analisis menunjukkan bahwa ada perubahan sikap dari kategori tinggi ke kategori rendah sebanyak 5 orang responden, ada perubahan dari kategori rendah ke kategori tinggi sebanyak 5 orang responden, dan terjadi kategori yang tidak berubah, seperti kategori sikap "baik" sebelum dan sesudah sama atau kategori sikap "kurang" sebelum dan sesudahnya sama sebanyak 24 orang responden. Hasil uji wilcoxon menunjukkan $\mathrm{p}(0,414)>\alpha(=0,05)$. Artinya tidak ada 


\begin{tabular}{|c|c|c|c|c|}
\hline Sikap & Sebelum & Sesudah & Perubahan & Nilai \\
\cline { 2 - 3 } Rangking & $\mathrm{P}$ \\
\hline Baik & 12 & 29 & $\begin{array}{c}\text { Rangking } \\
\text { Negatif }=2\end{array}$ & \multirow{2}{*}{0,00} \\
Kurang & 22 & 5 & $\begin{array}{c}\text { Rangking } \\
\text { Positif }=32\end{array}$ & $\begin{array}{c}0 \\
0\end{array}$ \\
\hline & & & Ties $=0$ & \\
\hline
\end{tabular}

perubahan pengetahuan pada kelompok kontrol sebelum dan sesudah kelas ibu hamil.

\subsubsection{Perubahan Pengetahuan dan Sikap pada Kelompok Perlakuan Sebelum dan Sesudah Test}

Untuk melihat perubahan pengetahuan dan sikap pada kelompok control sebelum dan sesudah kelas ibu hamil dilakukan dengan menggunakan uji Wilcoxon. Hasil analisis dapat dilihat pada tabel berikut ini

Tabel 4.9 Perubahan pengetahuan pada kelompok perlakuan sebelum dan sesudah test

\begin{tabular}{|c|c|c|c|c|}
\hline Pengetahuan & Sebelum & Sesudah & $\begin{array}{c}\text { Perubahan } \\
\text { Rangking }\end{array}$ & $\begin{array}{c}\text { Nilai } \\
\mathrm{P}\end{array}$ \\
\cline { 2 - 4 } & $\mathrm{n}$ & $\mathrm{n}$ & $\begin{array}{c}\text { Rangking } \\
\text { Negatif }=0\end{array}$ & \multirow{2}{*}{0,000} \\
\hline Cukup & 5 & 26 & $\begin{array}{c}\text { Rangking } \\
\text { Positif }=31\end{array}$ & \\
\hline Kurang & 29 & 8 & Ties = 3 & \\
\hline & & & \multicolumn{2}{|c}{} \\
\hline
\end{tabular}

Berdasarkan tabel di atas diperoleh keseluruhan pengetahuan sebelum kelas ibu hamil dalam kategori kurang yaitu 29 responden dan pengetahuan sesudah kelas ibu hamil semua responden dalam kategori kurang menjadi 8 orang responden.

Keterangan Uji Wilcoxon

Perubahan pengetahuan :

1. Ranking negatif adalah perubahan pengetahuan sebelum dan sesudah dari kategori "cukup menjadi kurang", atau kategori "baik menjadi kurang”, atau kategori "baik menjadi cukup".

2. Ranking positif adalah perubahan pengetahuan sebelum dan sesudah dari kategori "kurang menjadi cukup", atau kategori "kurang menjadi baik", atau kategori "cukup menjadi baik".

3. Ties artinya tidak terjadi perubahan sebelum dan sesudah kelas ibu hamil

Pada tabel diatas dilakukan uji wilcoxon untuk melihat perubahan tingkat pengetahuan, dari hasil analisis menunjukkan bahwa tidak ada perubahan dari kategori tinggi ke kategori rendah, ada perubahan dari kategori rendah ketinggi sebanyak 31 orang responden, dan terjadi kategori yang tidak berubah sebanyak 3 orang responden. Hasil uji wilcoxon menunjukkan $\mathrm{p}(0,000)<\alpha(=0,05)$. Artinya ada perubahan pengetahuan pada kelompok perlakuan sebelum dan sesudah kelas ibu hamil.
Tabel 4.10 Perubahan sikap pada kelompok perlakuan sebelum dan sesudah kelas ibu hamil

Berdasarkan tabel di atas diperoleh sikap sebelum kelas ibu hamil sebagian besar dalam kategori kurang yaitu 22 orang responden dan kategori baik 12 responden, dimana sikap sesudah kelas ibu hamil sebanyak 29 responden dalam kategori baik dan 5 orang responden dalam kategori kurang.

Keterangan Uji Wilcoxon

Perubahan sikap :

1. Ranking negatif adalah perubahan sikap sebelum dan sesudah dari kategori“baik menjadi kurang”.

2. Ranking positif adalah perubahan sikap sebelum dan sesudah dari kategori"kurang menjadi baik".

3. Ties artinya tidak terjadi perubahan sebelum dan sesudah kelas ibu hamil

Pada tabel diatas dilakukan uji wilcoxon untuk melihat perubahan sikap, dari hasil analisis menunjukkan bahwa ada perubahan sikap dari kategori tinggi ke kategori rendah sebanyak 2 orang responden, ada perubahan sikap dari kategori rendah ke kategori tinggi sebanyak 32 orang responden, dan terjadi kategori yang tidak berubah. Hasil uji wilcoxon menunjukkan $\mathrm{p}(0,000)<\alpha(=0,05)$. Artinya ada perubahan pengetahuan pada kelompok perlakuan sebelum dan sesudah kelas ibu hamil.

\subsubsection{Pengetahuan dan Sikap Responden tentang Perawatan Perawatan Kehamilan, Persalinan dan Nifas pada Kelompok Kontrol dan Kelompok Perlakuan Sesudah Kelas Ibu Hamil}

Untuk melihat perbedaan pengetahuan dan sikap responden pada kelompok perlakuan dan kontrol sesudah kelas ibu hamil dilakukan dengan menggunakan uji chi-square. Hasil analisis uji dapat dilihat pada tabel dibawah ini:

Tabel 4.11 Tabulasi silang pengetahuan tentang perawatan kehamilan,persalinan, dan nifas pada kelompok perlakuan dan kelompok controlsesudah kelas ibu hamil

\begin{tabular}{|c|c|c|c|c|c|c|c|}
\hline \multirow{3}{*}{ Pengetahuan } & \multicolumn{4}{|c|}{ Kelompok } & \multirow{2}{*}{\multicolumn{2}{|c|}{ Jumlah }} & \multirow{3}{*}{$\begin{array}{c}\text { Nilai } \\
\text { P }\end{array}$} \\
\hline & \multicolumn{2}{|c|}{ Kontrol } & \multicolumn{2}{|c|}{ Perlakuan } & & & \\
\hline & $\mathrm{n}$ & $\%$ & $\mathrm{n}$ & $\%$ & $\mathrm{n}$ & $\%$ & \\
\hline kurang & 31 & 79 & 8 & 21 & 39 & 100 & 0.00 \\
\hline cukup & 3 & 10,3 & 26 & 89,7 & 29 & 100 & 0 \\
\hline
\end{tabular}

Berdasarkan tabel 4.11 di atas diperoleh sebagian besar pengetahuan dalam kategori kurang 
yaitu 39 responden dimana pada kelompok kontrol sebanyak 31 responden $(79 \%)$ dan kelompok perlakuan sebanyak 8 responden $(21 \%)$. Hasil uji chisquare diperoleh nilai $p=0,000<\alpha(0,05)$, sehingga dapat disimpulkan bahwa ada perbedaan pengetahuan antara kelompok perlakuan dan kontrol sesudah kelas ibuhamil.

Tabel 4.12 Tabulasi silang sikap tentang perawatan kehamilan, persalinan, dan nifas pada kelompok perlakuan dan kelompok kontrol sesudah kelas ibu hamil

\begin{tabular}{|c|c|c|c|c|c|c|c|}
\hline \multirow{3}{*}{ Sikap } & \multicolumn{4}{|c|}{ Kelompok } & \multirow{2}{*}{ Jumlah } & \multirow{2}{*}{ Nilai P } \\
\cline { 2 - 7 } & \multicolumn{2}{|c|}{ Kontrol } & \multicolumn{2}{|c|}{ Perlakuan } & \multicolumn{2}{|c|}{} \\
\cline { 2 - 6 } & $\mathrm{n}$ & $\mathbf{\%}$ & $\mathrm{n}$ & $\mathbf{\%}$ & $\mathrm{n}$ & $\mathbf{\%}$ & \\
\hline Baik & 5 & 14,7 & 29 & 85,3 & 34 & 100 & \multirow{2}{*}{0.000} \\
\hline Kurang & 29 & 85,3 & 5 & 14,7 & 34 & 100 & \\
\hline
\end{tabular}

Berdasarkan tabel 4.12 di atas diperoleh data sikap dalam kategori kurang dan cukup yaitu 34 responden dimana pada kelompok kontrol sebanyak 32 responden $(94,1 \%)$ dan kelompok perlakuan sebanyak 29 responden $(5,9 \%)$. Hasil uji chi-square diperoleh nilai $p=0,000<\alpha(0,05)$, sehingga dapat disimpulkan bahwa ada perbedaan pengetahuan antara kelompok perlakuan dan kontrol sesudah kelas ibu hamil.

\subsection{Pembahasan Penelitian}

4.4.1 Pengaruh Kelas Ibu Hamil terhadap Pengetahuan Ibu tentang Perawatan Selama Kehamilan, Persalinan dan Nifas di Wilayah Kerja Puskesmas Pargarutan Kabupaten Tapanuli Selatan.

Meningkatkan pengetahuan ibu tentang pemeriksaan dan perawatan kehamilan adalah salah satu tujuan kelas ibu hamil. Pengetahuan ibu hamil tentang pemeriksaan dan perawatan kehamilan meliputi pengetahuan ibu tentang pengertian kehamilan, tanda kehamilan, keluhan yang sering dialami ibu hamil, perubahan fisik ibu hamil, perubahan emosional ibu hamil, jadwal pemeriksaan kehamilan, pelayanan kesehatan pada ibu hamil, menjaga ibu hamil dan janin sehat, hal-hal yang harus dihindari oleh ibu selama hamil, mitos/tabu, dan persiapan menghadapi persalinan (Kemkes RI, 2012).

Berdasarkan hasil penelitian dengan menggunakan uji chi-square diperoleh nilaip $=0,276$ $>\alpha(0,05)$, sehingga dapat disimpulkan bahwa tidak ada perbedaan pengetahuan antara kelompok kasus dan kontrol sebelum intervensi. Hasil uji wilcoxon menunjukkan $\mathrm{p}(0,000)<\alpha(=0,05)$. Artinya ada perubahan pengetahuan pada kelompok kontrol dan perlakuan sebelum dan sesudah intervensi. Sehingga dapat disimpulkan ada pengaruh kelas ibu hamil terhadap pengetahuan ibu tentang perawatanselama kehamilan, persalinan dan nifas di wilayah kerja puskesmas Pargarutan Kabupaten Tapanuli Selatan.

Hal ini sesuai dengan teori Notoatmodjo (2011) Pengetahuan merupakan hasil penginderaan manusia, atau hasil tahu seseorang terhadap objek melalui indra yang dimilikinya (mata, hidung, telinga, dan sebagainya). dengan sendirinya pada waktu penginderaan sehingga menghasilkan pengetahuan sangat dipengaruhi oleh intensitas perhatian dan persepsi terhadap objek. Sebagian besar pengetahuan seseorang diperoleh melalui indra pendengaran (telinga) dan indra penglihatan (mata). Hasil penelitian ini juga mendukung penelitian yang dilakukan oleh Harahap (2016) yang hasil penelitiannya menemukan bahwa kelas ibu hamil berpengaruh terhadap Pengetahuan Ibu tentang PerawatanSelama Kehamilan, Persalinan dan Nifas.

\subsubsection{Pengaruh Kelas Ibu Hamil terhadap Sikap Ibu tentang Perawatan Selama Kehamilan, Persalinan dan Nifas di Wilayah Kerja Puskesmas Pargarutan Kabupaten Tapanuli Selatan.}

Menurut Maulana (2012) yang mengutip Sarwono (1997), menyatakan bahwa sikap seseorang dapat berubah dengan diperolehnya tambahan informasi tentang objek tertentu, melalui persuasi serta tekanan dari kelompok sosialnya. Sikap dapat terbentuk dari adanya interaksi sosial yang dialami individu. Dalam hal ini interaksi sosial berupa kelas ibu hamil yang dilakukan di puskesmas Pargarutan Kabupaten Tapanuli Selatan.

Berdasarkan hasil penelitian dengan menggunakan uji chi-square diperoleh nilai $p=$ 0,000, sehingga dapat disimpulkan bahwa ada perbedaan sikap antara kelompok kasus dan kontrol sesudah intervensi. dan Hasil uji wilcoxon menunjukkan $\mathrm{p}(0,000)<\alpha(=0,05)$. Artinya tidak ada perubahan sikap pada kelompok kontrol dan perlakuan sebelum dan sesudah intervensi. Sehingga dapat disimpulkan bahwa ada pengaruh kelas ibu hamil terhadap sikap ibu tentang PerawatanSelama Kehamilan, Persalinan dan Nifas di Wilayah Kerja Puskesmas Pargarutan Kabupaten Tapanuli Selatan. Hasil penelitian ii sesuai dengan teori yang di ungkapkan oleh Sarwono (1997). Hasil penelitian ini juga mendukung penelitian yang dilakukan oleh Harahap (2016) yang menemukan bahwa kelas ibu hamil berpengaruh terhadap sikap ibu tentang perawatanselama kehamilan, persalinan dan nifas

\section{KESIMPULAN DAN SARAN 5.1 Kesimpulan}

Berdasarkan hasil penelitian dan pembahasan maka kesimpulan pada penelitian ini sebagai berikut ini : 
1. Tidak ada perubahan atau pengaruh pengetahuan tentang perawatan kehamilan, persalinan dan nifas pada kelompok kontrol sebelum dan sesudah kelas ibu hamil di wilayah kerja Puskesmas Pargarutan Kabupaten Tapanuli Selatan

2. Ada peningkatan pengetahuan ibu hamil tentang perawatan kehamilan, persalinan, dan nifas pada kelompok perlakuan setelah diberikan intervensi kelas ibu hamil di wilayah kerja Puskesmas Pargarutan Kabupaten Tapanuli Selatan

3. Ada peningkatan Sikap ibu hamil tentang perawatan kehamilan, persalinan, dan nifas pada kelompok perlakuan setelah diberikan intervensi kelas ibu hamil di wilayah kerja Puskesmas Pargarutan Kabupaten Tapanuli Selatan

4. Ada perubahan atau pengaruh sikap tentang perawatan kehamilan, persalinan dan nifas pada kelompok perlakuan sebelum dan sesudah kelas ibu hamil di wilayah kerja Puskesmas Pargarutan Kabupaten Tapanuli Selatan

5. Ada perubahan atau pengaruh pengetahuan dan sikap tentang perawatan kehamilan, persalinan dan nifas pada kelompok perlakuan sebelum dan sesudah kelas ibu hamil di wilayah kerja Puskesmas Pargarutan Kabupaten Tapanuli Selatan

\subsection{Saran}

1. Kelas ibu hamil harus tetap dilakukan karena memberikan pengaruh yang baik bagi pengetahuan dan sikap ibu hamil tentang kehamilan, persalinan dan nifas di wilayah kerja Puskesmas Pargarutan Kabupaten Tapanuli Selatan.

2. Seluruh petugas puskesmas Pargarutan Kabupaten Tapanuli Selatan harus lebih giat lagi melakukan sosialisasi ke masyarakat khususnya ibu hamil agar peminat dari kelas ibu hamil semakin meningkat.

3. Puskesmas Pargarutan Kabupaten Tapanuli Selatan sebaiknya melakukan pelatihan kepada seluruh perangkat di puskesmas seperti bidan desa dan fasilitator agar lebih kompeten dalam melakukan kelas ibu hamil.

4. Meningkatkan kerjasama terhadap pihak-pihak terkait sehingga dapat mendukung kegiatan program kesehatan melalui dana desa dan mengusulkan anggaran khususnya untuk kelas ibu hamil.
Ambarwati, 2009. Asuhan Kebidanan Nifas. Yogyakarta : Mitra Cendikia

Azwar, S., 2003. Reliabilitas dan Validitas, Yogyakarta :Pustaka Pelajar.

Arikunto, S., 2006. Prosedur Penelitian, Suatu Pendekatan Praktik, Edisi Revisi VI,Jakarta :Rineka Cipta.

Bobak, Jensen dan Lowdermilk., 2004, Maternity Nursing, 7 Th ed. St Louis; Mosby

Dahlan, M. S., 2004. Statistika Untuk Kedokteran dan Kesehatan, Uji Hipotesis dengan Menggunakan SPSS, Jakarta : Arkans.

Depkes RI, 2007. Materi Ajar Penurunan Kematian Ibu dan Bayi Baru Lahir, Jakarta.

Depkes RI, 2007. Pedoman Pelayanan Antenatal, Jakarta.

Kementerian Kesehatan Republik Indonesia, 2011. Pedoman Pelaksanaan Kelas Ibu Hamil, Jakarta.

Kusmiyati, dkk, 2009, Perawatan Ibu Hamil (Asuhan Ibu Hamil), Yogyakarta; Cetakan kw-3, Penerbit Fitramaya.

\section{DAFTAR PUSTAKA}

